\title{
Differential Efficiencies of Dip-net Sampling versus Sampling Surface-floating Pupal Exuviae in a Biodiversity Survey of Chironomidae
}

\author{
Leonard C. Ferrington Jr. ${ }^{1}$ and William P. Coffman ${ }^{2}$ \\ ${ }^{1}$ Department of Entomology, University of Minnesota, 219 Hodson Hall, 1980 Folwell Avenue, Saint \\ Paul, MN, USA 55108-6125.E-mail:ferri016@umn.edu \\ ${ }^{2}$ Department of Biological Sciences, University of Pittsburgh, Crawford Hall, Pittsburgh, PA, USA 15260. \\ Published posthumously
}

\begin{abstract}
Relative efficiencies of standard dip-net sampling (SDN) versus collections of surface-floating pupal exuviae (SFPE) were determined for detecting Chironomidae at catchment and site scales and at subfamily/tribe-, genus- and species-levels based on simultaneous, equal-effort sampling on a monthly basis for one year during a biodiversity assessment of Bear Run Nature Reserve. Results showed SFPE was more efficient than SDN at catchment scales for detecting both genera and species. At site scales, SDN sampling was more efficient for assessment of a first-order site. No consistent pattern, except for better efficiency of SFPE to detect Orthocladiinae genera, was observed at genus-level for two second-order sites. However, SFPE was consistently more efficient at detecting species of Orthocladiinae, Chironomini and Tanytarsini at the second order sites. SFPE was more efficient at detecting both genera and species at two third-order sites. The differential efficiencies of the two methods are concluded to be related to stream order and size, substrate size, flow and water velocity, depth and habitat heterogeneity, and differential ability to discriminate species among pupal exuviae specimens versus larval specimens. Although both approaches are considered necessary for comprehensive biodiversity assessments of Chironomidae, our results suggest that there is an optimal, but different, allocation of sampling effort for detecting Chironomidae across stream orders and at differing spatial and taxonomic scales.
\end{abstract}

\section{Introduction}

Standardized dip-net (SDN) sampling for bioassessment of aquatic insects in water quality monitoring programs is a collection method endorsed by the US Environmental Protection Agency (Barbour et al. 1999) and has been widely adopted by state agencies and private corporations. Although widely adopted, sample processing and identification of larval chironomids collected using this method is a time-consuming activity, even when family, subfamily or tribe-level identification are the measurement end-point, and more efficient methods could result in decreased costs to water quality monitoring programs.

By contrast to SDN sampling, collections of surface-floating pupal exuviae (SFPE) have been shown to be a more time-efficient approach to assessing chironomid composition in a variety of stream settings (Anderson and Ferrington 2012, Bouchard and Ferrington 2011, Ferrington et al. 1991, Sealock and Ferrington 2008). However, no comparisons of the results of simultaneous collections using both methods have been made across stream stretches of differing order in catchments with good water quality and high habitat conditions in the United States, so it is not possible to determine how effective collections of SFPE are in resolving chironomid composition.

For this paper, we have re-analyzed historical data from a biodiversity assessment of aquatic invertebrates of the Bear Run Nature Preserve (BRNR) to calculate the comparative efficiencies of detecting chironomids using both SDN and SFPE methods at sites located on first- through third-order stream stretches. Questions we sought to answer were: what are the comparative efficiencies of detecting chironomid compositions at (1) catchment-scale, (2) stream order scale and (3) at differing taxonomic levels (subfamily/tribe, genus and species levels).

\section{Materials and Methods}

\section{Catchment}

The Bear Run Nature Reserve is located adjacent to PA Route 381, approximately 3 miles south of Mill Run, Stewart Township and Springfield Township in Fayette County, southwestern Pennsylvania. The BRNR is approximately 5,079 acres, most of which has been protected since 1963. Two streams, Bear Run and Lick Run, and their unnamed springs, seeps and small spring runs drain the BRNR.

The plant community types in the reserve range from regenerating old fields and conifer planta- 
tions to second-growth deciduous and hemlock forests. Dominant trees include tulip tree, red maple, chestnut oak, sugar maple, and black cherry. American beech is dominant in the upper Bear Run and Lick Run riparian areas. Stands of eastern hemlock occur in the major drainages, especially along Bear Run. Understory forest plants include spicebush, rosebay rhododendron, smooth azalea, witch hazel, and mountain laurel. Wildflowers include moccasin flower, trailing arbutus, painted trillium, Solomon's seal, yellow violet, and sweet violet.

\section{Sample Sites}

Five sample sites were defined on first-order (one, referred to as Site 1), second-order (two, referred to as Sites 2 and 5) and third-order (two, referred to as Sites 3 and 4) stretches of stream. At each site, SDN sampling was done by one of us (LCF) along approximately 10 meters of stream and collections of SFPE were taken (WPC) along approximately 60 meters of stream. On each collection date and at each sample site, the time and effort for each method were similar.

Site 1 (first-order) was located where the stream crosses Rhododendron Trail. The stream varied between 0.5 to approximately 1.2 meters wide and up to $15 \mathrm{~cm}$ depth. Stream substrates consisted of rounded boulder, intermixed with sand and gravels. Woody debris was also common. The entire stream site consisted of erosional areas, without well-developed pool or glide habitats and slow water velocity which, in July/August, were further reduced to trickle with barely visible water movement.

Site 2 (second-order) was located downstream of Site 1, where the stream crosses under Ridge Trail. The stream varied between 0.8 to approximately 1.2 meters wide and up to $25 \mathrm{~cm}$ depth. Stream substrates consisted of smaller amounts of rounded boulder and sand than Site 1, but greater proportion of gravels. Woody debris was also common. The entire stream site consisted of erosional areas, without well-developed pool or glide habitats. Water velocity was intermediate of sites sampled, and flow was nearly constant across sample dates, even during July/August.

Site 3 (third-order) was located on Bear Run, where the stream crosses under Arbutus Trail. The stream varied between 2.5 to approximately 5.0 meters wide and was often greater than 1.0 meters depth. Stream substrates were highly heterogeneous, and consisted of gravel, cobble and boulder in well-developed riffles, to sand and finer mud in pools. Woody debris was present, but less common than Sites 1 and 2. Water velocity in riffles was highest of all sites sampled, and flow was nearly constant across sample dates.

Site 4 (third-order) was located on Bear Run, approximately 1.2 kilometers stream-distance downstream of Site 3, where the stream crosses under PA Route 381 . The stream varied between approximately 4.0 meters to greater than 5.0 meters wide and up to approximately 0.8 meters depth. Stream substrates were highly heterogeneous, and consisted of gravel, cobble and boulder in well-developed riffles to sand and finer mud in pools. Woody debris was present, but less common than Sites 1, 2 and 3. Water velocity in riffles was less than Site 3 due to less local gradient of slope, and flow was nearly constant across sample dates.

Site 5 (second-order) was located on a tributary of Bear Run that intersects upstream of Site 3 and is upstream of where Hemlock trail crosses this tributary near the south edge of the reserve. This tributary varied between 0.6 to approximately 1.6 meters wide and up to $25 \mathrm{~cm}$ depth. Stream substrates consisted of smaller amounts of rounded boulder and sand than Site 1, but greater proportion of gravels similar to substrates at Site 2. Woody debris was also common. The entire stream site consisted of erosional areas, without well-developed pool or glide habitats. Water velocity was intermediate of sites sampled, and flow was nearly constant across sample dates, even during July/August. This site is the only stretch of stream that flowed through unprotected areas of land, approximately 100 meters stream-distance upstream.

\section{Sampling Methods}

Dip-net sampling was performed consistent with the method described in Barber et al. (1999), except that on each sample date some marginal leaflitter, submerged or partially submerged wood, and larger boulders were inspected and larval specimens from these substrates were hand-picked and added to the sample in the field. SFPE were collected consistent with the method described in Ferrington et al. (1991). This method targets areas where detritus is accumulated by currents and also accumulations of floating foams in which floating pupal exuviae can become entrained. SDN and SFPE samples were both preserved in the field with $70 \%$ Ethanol and returned to lab for sorting under 6-12X magnification.

Samples from each site were collected on the same date, approximately monthly from September 1975 through August 1976. At each sample site on each collection date the timed effort spent sampling was similar, but timed effort varied slightly 
from winter (less time) to summer. In addition, the SDN samples were strongly oriented to riffle-like conditions and deeper pool habitats were inefficiently sampled.

\section{Specimen Preparation and Identification}

Larval and pupal exuviae specimens were dehydrated in $95 \%$ Ethanol then slide-mounted in Euparol for identification using primary literature available at the time of collection. Identifications of larvae and pupal exuviae were performed independently and at the end of the project, our identifications were reconciled by sample site and cumulative lists of species were assembled for each sample site and for the entire catchment. Voucher collections were assembled. The larval vouchers are deposited at the University of Minnesota Insect Collection and the pupal exuviae specimens are deposited at the William P. Coffman lab at the La Selva Biological Station in Costa Rica. Nomenclature for all taxa has been updated to reflect current generic and species definitions, and larval vouchers have been reviewed for quality assurance.

\section{Results}

A total of 7,329 larvae and 8,508 pupal evuviae were collected during this study. Substantially more larvae were collected at Site 1 (1,068 larvae versus 177 pupal exuviae) and Site 5 (3,283 versus $2,153)$ than pupal evuviae. By contrast, more pupal exuviae were collected at Site 2 (1,993 exuviae versus 964 larvae), Site 3 (1,879 versus 1,044) and Site 4 (2,306 versus 970). Relative to SDN, SFPE samples yielded more specimens as stream order increased.

Results showed SFPE was more efficient than SDN at catchment scales for detecting both genera and species (Table 1). Across all sample sites, 74 genera and 134 species were detected. SDN collections of larvae detected 49 genera $(66.2 \%$ of total genera) and 77 species (57.5\% of total species). By contrast, collections of SFPE detected 72 genera $(97.3 \%)$ and 128 species $(95.5 \%)$. Only the genera Larsia (1 species, 15 larval specimens) and Natarsia (1 species, 1 larval specimen) were not detected as SFPE.

Table 1. Number of taxa (genera, species) detected and the relative detection percentages for larval collections versus collections of SFPE.

\begin{tabular}{|c|c|c|c|c|c|}
\hline & Total taxa & Taxa as larvae & $\%$ of total & Taxa as SFPE & $\%$ of total \\
\hline $\begin{array}{l}\text { Cumulative } \\
\text { project totals } \\
\text { (Genera) }\end{array}$ & 74 & 49 & 66.2 & 72 & 97.3 \\
\hline $\begin{array}{l}\text { Cumulative } \\
\text { project totals } \\
\text { (Species) }\end{array}$ & 134 & 77 & 57.5 & 128 & 95.5 \\
\hline \multicolumn{6}{|l|}{ First order } \\
\hline Site 1 (Genera) & 26 & 23 & 88.5 & 16 & 61.5 \\
\hline Site 1 (Species & 35 & 28 & 80.0 & 17 & 48.6 \\
\hline \multicolumn{6}{|l|}{ Second order } \\
\hline Site 2 (Genera) & 35 & 27 & 77.1 & 26 & 74.3 \\
\hline Site 2 (Species) & 56 & 35 & 62.5 & 44 & 78.6 \\
\hline Site 5 (Genera) & 52 & 33 & 63.5 & 46 & 88.5 \\
\hline Site 5 (Species) & 89 & 51 & 57.3 & 69 & 77.5 \\
\hline \multicolumn{6}{|l|}{ Third order } \\
\hline Site 3 (Genera) & 56 & 32 & 57.1 & 51 & 91.1 \\
\hline Site 3 (Species) & 93 & 49 & 52.7 & 83 & 89.2 \\
\hline Site 4 (Genera) & 49 & 31 & 63.3 & 48 & 98.0 \\
\hline Site 4 (Species) & 92 & 51 & 55.4 & 83 & 90.2 \\
\hline
\end{tabular}


Detection efficiencies varied by method at stream order scale (Table 1). At Site 1 (first order stretch of stream), 26 genera and 35 species were detected. SDN collections of larvae detected 23 genera ( $88.5 \%$ of genera detected at this sample site) and 28 species $(80 \%$ of species detected). Collections of SFPE were less efficient at detecting genera (16, $61.5 \%)$ and species $(17,48.6 \%)$. The only genera not detected as larvae were Pseudorthocladius (1 species, 9 specimens of SFPE), Mesocricotopus (1 species, 1 specimen) and Krenosmittia (1 species, 2 specimens).

Sample Sites 2 and 5 were located on second order stretches of stream, but had substantially different generic (35 versus 52 genera) and species (56 versus 89 species) richness values. Detection efficiencies did not differ appreciably by method at detecting genera at Sample Site 2 (27 genera detected by SDN of larvae versus 26 as SFPE). However, detection efficiency differed markedly by method at Sample site 5, where 33 genera were detected as larvae by SDN but 46 genera were detected as SFPE. In addition, detection efficiencies differed substantially by method at species-level both within and across the two sample sites. At Sample Site 2, 35 species were detected as larvae by SDN (62.5\% of total species) versus 44 detected as SFPE (78.6\%). The respective totals for Sample
Site 5 were 51 species $(57.3 \%)$ detected as larvae by SDN versus 69 (77.5\%) detected as SFPE.

Sample Sites 3 and 4 were located on the same third order stretch of stream and had similar generic (56 and 49 genera, respectively) and species richness (93 and 92 species, respectively). Detection efficiencies of larval collections were similar across both sites, with 32 genera (57.1\%) detected at Site 3 and 31 genera $(63.3 \%)$ detected at Site 4. Detection efficiencies of SFPE collections were higher for collections of SFPE across both of the sites compared to larval collections, but were also similar across the two sites, with 51 genera (91.1\%) detected at Site 3 and 48 genera $(98.0 \%)$ detected at Site 4 . At the species level, larval collections detected 49 species $(52.7 \%)$ at Site 3 and 51 species $(55.4 \%)$ at Site 4 . SFPE collections detected 83 species at each site, representing 89.2\% and $90.2 \%$ of species, respectively, for Site 3 and 4.

The relative efficiencies of the two collection methods varied by taxonomic level (at subfamily/tribe, Tables 2-5, and genus/species, Table 6). Summarized across all sample sites and collection dates, SDN were never more efficient at detecting chironomid genera in the catchment of the Bear Run Nature Reserve than SFPE. Summarized at

Table 2. Number of taxa (genera, species, summed across all sites) detected by subfamily or tribe and the relative detection percentages for larval collections versus collections of SFPE.

\begin{tabular}{|c|c|c|c|c|c|}
\hline & Total taxa & Taxa as larvae & $\%$ of total & Taxa as SFPE & $\%$ of total \\
\hline \multicolumn{6}{|c|}{ Sample site totals, genera } \\
\hline Tanypodinae & 12 & 7 & 58.3 & 10 & 83.3 \\
\hline Diamesinae & 2 & 2 & 100.0 & 2 & 100.0 \\
\hline Prodiamesinae & 2 & 1 & 50.0 & 2 & 100.0 \\
\hline Orthocladiinae & 33 & 24 & 72.7 & 33 & 100.0 \\
\hline \multicolumn{6}{|l|}{ Chironominae } \\
\hline Chironomini & 15 & 7 & 46.7 & 15 & 100.0 \\
\hline Pseudochironomini & 1 & 0 & 0.0 & 1 & 100.0 \\
\hline Tanytarsini & 9 & 8 & 88.9 & 9 & 100.0 \\
\hline \multicolumn{6}{|c|}{ Sample site totals, species } \\
\hline Tanypodinae & 15 & 9 & 60.0 & 13 & 86.7 \\
\hline Diamesinae & 3 & 3 & 100.0 & 2 & 66.7 \\
\hline Prodiamesinae & 2 & 1 & 50.0 & 2 & 100.0 \\
\hline Orthocladiinae & 68 & 41 & 60.3 & 67 & 98.5 \\
\hline \multicolumn{6}{|l|}{ Chironominae } \\
\hline Chironomini & 22 & 10 & 45.5 & 22 & 100.0 \\
\hline Pseudochironomini & 1 & 0 & 0.0 & 1 & 100.0 \\
\hline Tanytarsini & 23 & 13 & 56.5 & 21 & 91.3 \\
\hline
\end{tabular}


the species level, SDN were only more efficient at detecting Diamesinae species (3 versus 2 species) compared to SFPE. By contrast, however, SFPE were much more efficient at detecting genera of Tanypodinae and Prodiamesinae than SDN, and even more efficient at detecting species within the subfamilies Tanypodinae, Prodiamesinae and Orthocladiinae and the tribes Chironomini, Pseudochironomini and Tanytarsini of the subfamily Chironominae.

SDN was always more efficient or equal in efficiency at detecting species within subfamilies or tribes at Site 1 (Table 3); this was also true for detection efficiency at genus-level except for Orthocladiinae, where SFPE was $6.7 \%$ more efficient at detecting genera.

For sites on second order stretches of stream, at the genus-level, no consistent trends in efficiencies of either method occurred except for Orthocladiinae, where the SFPE method consistently was more efficient than SDN collections (Table 4). At species-level, however, the SFPE consistently was more efficient for Orthocladiinae, Chironomini and Tanytarsini, but SDN was more efficient for Diamesinae. No consistent pattern was observed for Tanypodinae.

For sites on third order stretches of stream, SFPE consistently was more efficient at detecting both genera and species of Orthocladiinae, Chironomini and Tanytarsini (Table 5). SDN only consistently outperformed SFPE detecting genera and species of Diamesinae.

Table 6 lists the genera that were most species rich across all sample sites and the species detected by each method. The genera Eukiefferiella (9 species), Tanytarsus (9 species), Cricotopus (8 species) and Orthocladius (subgenus Orthocladius) (6 species) were the most species richness, and all species of these genera were detected as SFPE. SDN collections of larvae were less efficient at detecting species in these genera $(88.9 \%$ to $16.7 \%$ detected). Fifty of the genera detected at BRNP were each represented by only a single species and 48 of the genera were detected as SFPE (96\%) versus only 25 of the genera detected as larvae using SDN sampling (50\%).

\section{Discussion}

Comprehensive surveys of Chironomidae biodiversity across stream orders or at catchment scales require substantial sampling effort in seasonal environments such as those that occur at latitudes similar to that of the Bear Run Nature Reserve, and are best achieved using multiple field methods targeting all developing life stages. The results of this

Table 3. Number of taxa (genera, species) detected by subfamily or tribe and the relative detection percentages for larval collections versus collections of SFPE at Site 1, the first order stretch of stream.

\begin{tabular}{|c|c|c|c|c|c|}
\hline & Total taxa & Taxa as larvae & $\%$ of total & Taxa as SFPE & $\%$ of total \\
\hline \multicolumn{6}{|c|}{ Sample site totals, genera } \\
\hline Tanypodinae & 1 & 1 & 100.0 & 1 & 100.0 \\
\hline Diamesinae & 1 & 1 & 100.0 & 0 & 0.0 \\
\hline Prodiamesinae & 0 & 0 & 0.0 & 0 & 0.0 \\
\hline Orthocladiinae & 15 & 12 & 80.0 & 13 & 86.7 \\
\hline \multicolumn{6}{|l|}{ Chironominae } \\
\hline Chironomini & 4 & 4 & 100.0 & 0 & 0.0 \\
\hline Pseudochironomini & 0 & 0 & 0.0 & 0 & 0.0 \\
\hline Tanytarsini & 5 & 5 & 100.0 & 2 & 40.0 \\
\hline \multicolumn{6}{|c|}{ Sample site totals, species } \\
\hline Tanypodinae & 2 & 2 & 100.0 & 1 & 50.0 \\
\hline Diamesinae & 1 & 1 & 100.0 & 0 & 0.0 \\
\hline Prodiamesinae & 0 & 0 & 0.0 & 0 & 0.0 \\
\hline Orthocladiinae & 20 & 14 & 70.0 & 13 & 65.0 \\
\hline \multicolumn{6}{|l|}{ Chironominae } \\
\hline Chironomini & 5 & 5 & 100.0 & 0 & 0.0 \\
\hline Pseudochironomini & 0 & 0 & 0.0 & 0 & 0.0 \\
\hline Tanytarsini & 7 & 6 & 85.7 & 3 & 42.9 \\
\hline
\end{tabular}


Table 4: Number of taxa (genera, species) detected by subfamily or tribe and the relative detection percentages for collections of larvae versus SFPE at Sites 2 and 5, the second order stretches of stream.

\begin{tabular}{|c|c|c|c|c|c|}
\hline & Total taxa & Taxa as larvae & $\%$ of total & Taxa as SFPE & $\%$ of total \\
\hline \multicolumn{6}{|l|}{ SITE 2} \\
\hline \multicolumn{6}{|c|}{ Sample site totals, genera } \\
\hline Tanypodinae & 3 & 3 & 100.0 & 1 & 33.3 \\
\hline Diamesinae & 2 & 2 & 100.0 & 0 & 0.0 \\
\hline Prodiamesinae & 0 & 0 & 0.0 & 0 & 0.0 \\
\hline Orthocladiinae & 16 & 13 & 81.3 & 15 & 93.7 \\
\hline \multicolumn{6}{|l|}{ Chironominae } \\
\hline Chironomini & 7 & 5 & 71.4 & 5 & 71.4 \\
\hline Pseudochironomini & 0 & 0 & 0.0 & 0 & 0.0 \\
\hline Tanytarsini & 5 & 4 & 80.0 & 3 & 60.0 \\
\hline \multicolumn{6}{|c|}{ Sample site totals, species } \\
\hline Tanypodinae & 4 & 4 & 100.0 & 2 & 50.0 \\
\hline Diamesinae & 2 & 2 & 100.0 & 0 & 0.0 \\
\hline Prodiamesinae & 0 & 0 & 0.0 & 0 & 0.0 \\
\hline Orthocladiinae & 33 & 18 & 54.5 & 29 & 87.9 \\
\hline \multicolumn{6}{|l|}{ Chironominae } \\
\hline Chironomini & 9 & 6 & 66.7 & 7 & 77.8 \\
\hline Pseudochironomini & 0 & 0 & 0 & 0 & 0 \\
\hline Tanytarsini & 8 & 5 & 62.5 & 6 & 75.0 \\
\hline \multicolumn{6}{|l|}{ SITE 5} \\
\hline \multicolumn{6}{|c|}{ Sample site totals, genera } \\
\hline Tanypodinae & 7 & 4 & 57.1 & 6 & 85.7 \\
\hline Diamesinae & 1 & 1 & 100.0 & 1 & 100.0 \\
\hline Prodiamesinae & 0 & 0 & 0.0 & 0 & 0.0 \\
\hline Orthocladiinae & 24 & 18 & 75.0 & 23 & 95.8 \\
\hline \multicolumn{6}{|l|}{ Chironominae } \\
\hline Chironomini & 11 & 6 & 54.5 & 10 & 90.9 \\
\hline Pseudochironomini & 1 & 0 & 0.0 & 1 & 100.0 \\
\hline Tanytarsini & 8 & 5 & 62.5 & 7 & 87.5 \\
\hline \multicolumn{6}{|c|}{ Sample site totals, species } \\
\hline Tanypodinae & 9 & 5 & 55.6 & 7 & 77.8 \\
\hline Diamesinae & 2 & 2 & 100.0 & 1 & 50.0 \\
\hline Prodiamesinae & 0 & 0 & 0.0 & 0 & 0.0 \\
\hline Orthocladiinae & 44 & 28 & 63.6 & 36 & 81.8 \\
\hline \multicolumn{6}{|l|}{ Chironominae } \\
\hline Chironomini & 17 & 9 & 52.9 & 12 & 70.6 \\
\hline Pseudochironomini & 1 & 0 & 0.0 & 1 & 100.0 \\
\hline Tanytarsini & 16 & 8 & 50.0 & 12 & 75.0 \\
\hline
\end{tabular}


Table 5: Number of taxa (genera, species) detected by subfamily or tribe and the relative detection percentages for collections of larvae versus SFPE at Sites 3 and 4, the third order stretches of stream.

\begin{tabular}{|c|c|c|c|c|c|}
\hline & Total taxa & Taxa as larvae & $\%$ of total & Taxa as SFPE & $\%$ of total \\
\hline \multicolumn{6}{|l|}{ SITE 3} \\
\hline \multicolumn{6}{|c|}{ Sample site totals, genera } \\
\hline Tanypodinae & 6 & 3 & 50.0 & 6 & 100.0 \\
\hline Diamesinae & 2 & 2 & 100.0 & 1 & 50.0 \\
\hline Prodiamesinae & 2 & 1 & 50.0 & 2 & 100.0 \\
\hline Orthocladiinae & 28 & 15 & 53.6 & 27 & 96.4 \\
\hline \multicolumn{6}{|l|}{ Chironominae } \\
\hline Chironomini & 10 & 5 & 50.0 & 7 & 70.0 \\
\hline Pseudochironomini & 0 & 0 & 0.0 & 0 & 0.0 \\
\hline Tanytarsini & 7 & 6 & 85.7 & 7 & 100.0 \\
\hline \multicolumn{6}{|c|}{ Sample site totals, species } \\
\hline Tanypodinae & 8 & 4 & 50.0 & 6 & 75.0 \\
\hline Diamesinae & 2 & 2 & 100.0 & 1 & 50.0 \\
\hline Prodiamesinae & 2 & 1 & 50.0 & 2 & 100.0 \\
\hline Orthocladiinae & 52 & 26 & 50.0 & 46 & 88.5 \\
\hline \multicolumn{6}{|l|}{ Chironominae } \\
\hline Chironomini & 13 & 7 & 53.8 & 12 & 92.3 \\
\hline Pseudochironomini & 0 & 0 & 0.0 & 0 & 0.0 \\
\hline Tanytarsini & 16 & 9 & 56.3 & 16 & 100.0 \\
\hline \multicolumn{6}{|l|}{ SITE 4} \\
\hline \multicolumn{6}{|c|}{ Sample site totals, genera } \\
\hline Tanypodinae & 6 & 4 & 66.7 & 6 & 100.0 \\
\hline Diamesinae & 2 & 2 & 100.0 & 1 & 50.0 \\
\hline Prodiamesinae & 0 & 0 & 0.0 & 0 & 0.0 \\
\hline Orthocladiinae & 25 & 16 & 64.0 & 25 & 100.0 \\
\hline \multicolumn{6}{|l|}{ Chironominae } \\
\hline Chironomini & 7 & 3 & 42.9 & 7 & 100.0 \\
\hline Pseudochironomini & 0 & 0 & 0.0 & 0 & 0.0 \\
\hline Tanytarsini & 10 & 6 & 60.0 & 9 & 90.0 \\
\hline \multicolumn{6}{|c|}{ Sample site totals, species } \\
\hline Tanypodinae & 8 & 6 & 75.0 & 6 & 75.0 \\
\hline Diamesinae & 2 & 2 & 100.0 & 1 & 50.0 \\
\hline Prodiamesinae & 0 & 0 & 0.0 & 0 & 0.0 \\
\hline Orthocladiinae & 51 & 26 & 51.0 & 48 & 94.1 \\
\hline \multicolumn{6}{|l|}{ Chironominae } \\
\hline Chironomini & 11 & 5 & 45.5 & 10 & 90.9 \\
\hline Pseudochironomini & 0 & 0 & 0.0 & 0 & 0.0 \\
\hline Tanytarsini & 20 & 9 & 45.0 & 18 & 90.0 \\
\hline
\end{tabular}


Table 6. Number of species detected by genus and the relative detection percentages for larval collections versus collections of SFPE.

\begin{tabular}{lccccc}
\hline Genus & Total species & Species as larvae & \% of total & Species as SFPE & \% of total \\
\hline Eukiefferiella & 9 & 8 & 88.9 & 9 & 100.0 \\
Tanytarsus & 9 & 3 & 33.3 & 9 & 100.0 \\
Cricotopus & 8 & 6 & 75.0 & 8 & 100.0 \\
Orthocladius (Ortho- & 6 & 1 & 16.7 & 6 & 100.0 \\
cladius) & & 2 & 50.0 & 4 & 100.0 \\
Corynoneura & 4 & 2 & 50.0 & 4 & 100.0 \\
Micropsectra & 4 & 2 & 50.0 & 4 & 100.0 \\
Parakiefferiella & 4 & 4 & 100.0 & 4 & 100.0 \\
Polypedilum & 4 & 3 & 100.0 & 3 & 100.0 \\
Conchapelopia & 3 & 1 & 33.3 & 3 & 100.0 \\
Microtendipes & 3 & 2 & 66.7 & 3 & 100.0 \\
Parametriocnemus & 3 & 2 & 66.7 & 3 & 100.0 \\
Thienemanniella & 3 & 1 & 50.0 & 2 & 100.0 \\
Brillia & 2 & 2 & 100.0 & 1 & 50.0 \\
Diamesa & 2 & 1 & 50.0 & 2 & 100.0 \\
Cryptochironomus & 2 & 1 & 50.0 & 2 & 100.0 \\
Krenosmittia & 2 & 1 & 50.0 & 2 & 100.0 \\
Nanocladius & 2 & 1 & 50.0 & 2 & 100.0 \\
Phaenopsectra & 2 & 1 & 50.0 & 2 & 100.0 \\
Procladius & 2 & 1 & 50.0 & 2 & 100.0 \\
Rheocricotopus & 2 & 1 & 50.0 & 2 & 100.0 \\
Rheotanytarsus & 2 & 2 & 100.0 & 1 & 50.0 \\
Stempellina & 2 & 2 & 100.0 & 2 & 100.0 \\
Stempellinella & 2 & 100.0 & 1 & 50.0 \\
Stilocladius & 2 & 50.0 & 48 & 96.0 \\
Genera represented by & 50 & 25 & & & \\
one species per genus & & & & & \\
\hline
\end{tabular}

project compare favorably to a more intensive field approach used by Coffman (1973) to study composition and phenology in Linesville Creek (134 species versus 143 species). However, the difference in species detected in the two studies suggests that more intensive sampling effort would result in higher species richness at BRNR.

Our field design, which incorporated monthly sampling events, is important in terms of interpreting our results. A concern related to the SFPE method is that it only detects taxa that are emerging at the time of collection, and in highly seasonal environments there is expected to be high temporal variability in species emergence (see Coffman 1989, Coffman and de la Rosa 1998). Consequently, a single annual SDN sample would likely detect more taxa as larvae than as pupal exuviae.

However, this pattern was not seen by Ferrington et al. (1991) in two organically enriched urban streams in Kansas, where there was strong congruence between larvae detected with SDN samples and pupal exuviae from SFPE samples; on the other hand SFPE was more efficient at detecting species as water quality conditions improved and species richness increased across sites. These results need to be interpreted cautiously, however, because the water quality and habitat conditions of the two streams assessed by Ferrington et al. (1991) were much poorer than exists at BRNR, and the species rich communities at Sites 2-5 may have much greater temporal emergence heterogeneity than the more enrichment-tolerant species of the streams in Kansas.

Given that budgetary limitations influence sample designs, the disparity in efficiencies of the two methods at the catchment-scale suggest that an al- 
ternative design consisting of more field sampling events using SFPE could be a more cost-efficient approach to assessing biodiversity than always collecting and processing the more time-consuming and costly SDN samples. However, the patterns of relative efficiency across sample sites with differing stream order suggest that there could be an optimal allocation of field effort employing the two methods among streams of differing orders, size and discharge in a catchment.

The higher efficiency of SDN at Site 1 reflects better coverage of microhabitats in small streams versus larger streams. This also strongly suggests that an equal-effort approach using SDN across streams of differing size will result in decreasing efficiency detecting chironomid taxa in larger streams. By contrast, the low efficiency of SFPE at Site 1 was likely due to difficulty using a pan to dip among large boulders in areas with minimal water depth. In addition, the slower water velocity and reduction to trickle-like flow conditions during summer also decreases the natural accumulating effect on floating pupal exuviae of currents in larger, deeper and faster flowing streams. Use of a drift net or smaller aquarium-size net that would fit into tighter spaces between rocks may have resulted in higher efficiency of collection of SFPE at this site. A drift net, however, would likely have needed to be in place for a 24-hour period or longer to filter a sufficient amount of stream flow, which would have added substantively to field efforts and sampling costs.

At BRNR, SFPE begins to outperform SDN in the transition from second order to third order sample sites characterized by well-developed pool/riffle conditions and widths exceeding about three meters. Our results for sample sites on second order stretches suggest that factors other than just size, flow and depth influence the efficiency of SFPE. These factors could include the size and space between larger boulders and the amount of woody debris extending into the water and creating conditions for back-flow and accumulation of floating detritus and pupal exuviae.

In addition to field sampling design, stream order and habitat conditions, the ability to resolve species is another variable that needs to be considered when comparing the efficiencies of the two methods. All genera detected in this study are welldefined and recognizable in both larval and pupal stages. Consequently, it can be argued that the differences in efficiencies at catchment-scale detection of genera are related to sampling error because of reduced efficiencies of SDN related to stream size, or difficulties sampling deeper pools, or specialized microhabitats of some larvae. However, at species-levels both sampling error and inability to resolve species-level difference among larvae are both sources of variability that decrease efficiency of SDN. The differential ability to resolve species is especially important in species-rich genera. Examples in this study include the genera Tanytarsus, Cricotopus, Orthocladius, Corynoneura, Micropsectra, Parakiefferiella and Microtendipes, where species level identifications of pupal exuviae are more readily achieved compared to identification of larvae.

The SDN sampling in this project was supplemented with targeted hand picking of marginal accumulations of wetted leaves, submerged and partially submerged wood of varying stages of decomposition, and larger boulders. Consequently, we detected larvae of some semi-aquatic species and xylophagic taxa that otherwise might have been undetected with SDN samples from coarser gravel/cobble substrates in riffles. Larvae from the targeted hand-picking efforts were included in the totals for SDN, likely increasing the efficiencies at the higher stream order sites. Despite this targeted effort, SFPE strongly out-performed our efforts aimed at detecting genera and species using larvae and whole pupae. SFPE also was slightly more effective at detecting phoretic taxa compared to the SDN technique.

\section{References}

Anderson, A.M. and Ferrington Jr, L.C. 2012. Time-Efficiency of Sorting Chironomidae Surface-Floating Pupal Exuviae Samples from Urban Trout Streams in Northeast Minnesota, USA. - Fauna norvegica 31: 19-23.

Barbour, M.T., Gerritsen, J., Snyder, B.D. and Stribling. J.B. 1999. Rapid Bioassessment Protocols for Use in Streams and Wadeable Rivers: Periphyton, Benthic Macroinvertebrates and Fish, Second Edition. EPA 841-B-99-002. U.S. Environmental Protection Agency; Office of Water; Washington, D.C.

Bouchard Jr., R. W. and Ferrington Jr., L.C. 2011. The effects of subsampling and sampling frequency on the use of surface-floating pupal exuviae to measure Chironomidae (Diptera) communities in wadeable temperate streams. - Environmental Monitoring and Assessment 181: 205-223.

Coffman, W.P. 1973. Energy flow in a woodland stream ecosystem. II. The taxonomic composition and phenology of the Chironomidae as 
determined by the collection of pupal exuviae. - Archiv für Hydrobiologie 71: 281-322.

Coffman, W.P. 1989. Factors that determine the species richness of lotic communities of Chironomidae. - Acta Biologica Debrecina Oecologica Hungarica 3: 95-100.

Coffman, W.P. and de la Rosa, C. 1998. Taxonomic composition and temporal organization of tropical and temperate species assemblages of lotic Chironomidae. - Journal of the Kansas Entomological Society 71: 388-406

Ferrington Jr., L.C., Blackwood, M.A., Wright, C.A., Crisp, N. H., Kavanaugh, J.L and Schmidt, F.J.. 1991. A protocol for using surface-floating pupal exuviae of Chironomidae for rapid bioassessment of changing water quality. pp.181-190. In: Sediment and Stream Water Quality in a Changing Environment: Trends and Explanations. IAHS Publication Number 203. 374 pp.

Sealock, A. W. and Ferrington Jr., L.C. 2008. Sampling efficiency of Chironomidae (Diptera) across disturbance gradients. - Boletim do $\mathrm{Mu}$ seu Municipal do Funchal (História Natural) No. 13: 85-92.

Article submitted 13. August 2014, accepted 31. October 2014, published 22. December 2014. 